\title{
HIGHER EDUCATION STUDENTS' EXPERIENCE IN A DIGITAL EDUCATIONAL MODALITY
}

\author{
Zubieta-Ramírez C*, Ayala-Aguirre FG, Olivares-Olivares SL, \\ Rodríguez-Pichardo CM, Mendoza-Moreno JA, Huereca-Alonzo S \\ and Yépiz-Guerrero MN \\ Tecnologico de Monterrey, Mexico
}

\begin{abstract}
In 2020, universities worldwide migrated abruptly from face-to-face education to an emergency remote distance format to respond to the SARS-CoV-2 pandemic. The present study aimed to assess this type of learning experience from higher education students' perspectives. A mixed-method design was conducted with 796 students from six different disciplinary schools. The questionnaire included five constructs (Pedagogical, Collaboration, Learning Resources, Time Management, and Functional Features) with 17 quantitative items rated on a 1-5 Likert scale (Cronbach's Alpha $=0.955)$. Answers from two open questions were coded into two categories: Positive Experiences and Aspects to Improve. The highest constructs were Functional Features (3.60) and Time Management (3.15). The lowest score was Collaboration (2.77). Students appreciated the digital experience using Zoom and Canvas and their flexibility with time and space in their selfmanagement. They recommended improving the interactions among peers and teachers with shorter and more interactive synchronous sessions. Even though there was only one week to prepare for the change from face-to-face to emergency remote distance learning, the students successfully continued their education. An updated distance teaching method was improved and implemented after reviewing the results of the present study. Since August 2020, more than 50 thousand higher education students have been taught via this enhanced digital educational modality.
\end{abstract}

Keywords: educational innovation, higher Education, digital education, flexible education, Zoom, canvas, SARS-CoV-2

\section{Introduction}

The SARS-CoV-2 pandemic ravages the world (Reimers \& Schleicher, 2020). According to UNESCO (2020), the nationwide mandatory quarantine has impacted over $91 \%$ of the students worldwide, which means that many students' educational needs have changed and need to be addressed differently. The pandemic forced universities to reformulate education to be adaptive, coherent, effective, and equitable (Reimers \& Schleicher, 2020).

Several authors (Bandaranaike et al., 2020; Bergdahl \& Nouri, 2020; Kamal et al., 2020; Radha et al., 2020; Reimers \& Schleicher, 2020; UNESCO, 2020; Zhu \& Liu, 2020) have mentioned specific factors that must be considered in education during the SARS outbreak: Pedagogy, Collaboration, Learning Resources, Time Management, and Functional Features.

The SARS-CoV-2 implies there must be changes related to pedagogical factors, beginning with the online experience. Previous authors (Bandaranaike et al., 2020; Bergdahl \& Nouri, 2020) explained 
that pedagogical strategies changed during the pandemic. Teachers must design student-centered didactic strategies, build social networks, motivate the students to engage, and guide them to learn new skills.

One of the main concerns in schools brought about by the pandemic is how to improve collaboration among students and teachers. Bergdahl and Nouri (2020) mentioned that collaboration is vital to consider when transforming the educational process during a pandemic. It facilitates the students' schoolwork and enables collective student-teacher interactions through various digital technologies to achieve educational goals.

Some features need to be considered regarding learning resources during a pandemic when education is transmitted online. They include proper instructional design to avoid students faltering in learning, developing their digital literacy, increasing discussions and collaboration among the students, motivating them, and providing appropriate feedback quickly.

Time management during the learning process has become crucial in the pandemic. According to Radha et al. (2020), the online method appears to suit most students because it enables them to access updated content when needed and choose their time for learning when it is convenient and comfortable.

Zhu and Liu (2020) have recommended strategies that take advantage of functional features during social distancing. These include using Zoom and other communication platforms, conducting online training to use learning resources, assembling a professional team to provide technical support, and ensuring that the students can participate in digital learning.

Bergdahl, N. and Nouri, J. (2020) have highlighted the need to be prepared and have backup plans during times of crisis, like a pandemic, to sustain schooling. So, it is relevant to study more about how a digital educational modality eases the transition to totally online education in an emergency that presents stark changes from the previous learning model. In the light of these considerations, our research team decided to build an instrument that allows higher education institutions to deal with educational issues that arise in unfamiliar contexts and unforeseen circumstances.

Olivares et al. (2021) proposed to analyze six quality dimensions for Massive Online Open Courses (MOOCs). Their model was adapted and designed to assess the students' perception of the distance learning modality implemented due to SARS-CoV-2. This study aimed to evaluate the students' perceptions of this digital educational modality implemented by the university to ensure higher education quality during the pandemic. 
Considering the previous studies mentioned, we designed a model with five quality dimensions. The studied constructs were pedagogy, collaboration, learning resources, time management, and functional features. Unlike the learning model assessment for MOOCs, the design aesthetics dimension was not included in the pandemic context analysis. In this research, the pedagogy dimension refers to the pedagogical approach, content, learning outcomes, and evaluation. The collaboration dimension considers aspects related to interactions and information flow. The learning resources dimension includes educational platforms, content presentations, and digital resources. The time management dimension refers to agenda and activity timing, and functional features considers how technological resources and educational platform functions facilitated learning and communication (Figure 1).
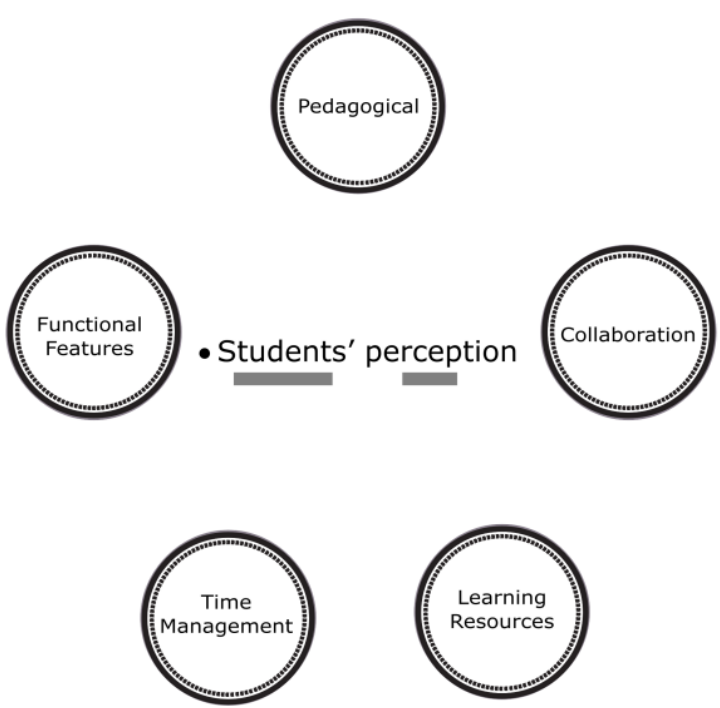

Figure 1: The proposed model to assess higher education students' perception.

\section{Literature review}

\section{A flexible and digital educational model}

According to Tecnologico de Monterrey (2020), a flexible and digital educational model is:

"A learning model that integrates innovative teaching strategies and cutting-edge technologies. The model proposes the design of a flexible and digital learning experience that combines the following academic components: Content, interaction, learning activities, technological tools, and evaluation." (Tecnologico de Monterrey, 2020, para 3)

Some of the digital modality features are flexibility, accompaniment, feedback from professors, interactive tools, availability of learning resources, active learning, and use of educational technology (Tecnologico de Monterrey, 2020).

\section{Pedagogical dimension}

Aini et al. (2020) reported how digital learning plays an essential role during a pandemic; however, it also challenges higher education institutions, students, and lecturers; therefore, the pedagogical dimension becomes essential for the well-functioning of the teaching and learning process. 
The pedagogical dimension of an e-learning modality implemented during a pandemic seeks to facilitate learning outcomes and assessment. Online learning platforms like Zoom allow educators and students to connect in real-time using video conferencing to improve communication (Rhada et al., 2020).

\section{Collaboration dimension}

Elzainy et al. (2020) explained that during the SARS-CoV-2 pandemic, it is essential to facilitate collaborative interaction in the online environment to optimize information flow and enhance peer sharing.

\section{Learning Resources dimension}

Almaiah et al. (2020) reported how important it is that universities focus on instilling the culture of elearning systems among students by training them to use educational platforms and digital resources effectively. This promotes the successful adoption of e-learning systems.

\section{Time Management dimension}

Rhada et al. (2020) declared that e-Learning during the SARS-CoV-2 confinement has made education available to many learners, with the advantage of choosing to learn at a convenient time, enabling them to access updated content whenever they want.

\section{Functional features}

Rannastu-Avalos and Siiman (2020) mentioned that virtual learning is a challenge for students because they may deal not only with technological issues but also cognitive and social ones. So, the appropriate functional features of e-learning systems help to address those issues.

\section{Justification}

Minghat et al. (2020) have pointed out the need to investigate students' perceptions of the online learning processes during the SARS-CoV-2 outbreak. This kind of investigation may provide inputs helpful in establishing educational strategies to improve the online experience.

It is vital to meet students' educational needs in times of crisis, such as SARS-CoV-2 (Şeker, 2020). Analyzing the students' experience in e-learning may help guide higher education institutions to fulfill the students' needs and prioritize the policies and strategies to implement remote learning effectively during a pandemic (Aini et al., 2020).

The instrument could offer higher education institutions an opportunity to focus on attending to the students' needs and defining roles and duties (Buzgan \& Güner, 2020). Studying the e-learning experience can lead universities to have a successful e-learning system (Almaiah et al., 2020). These kinds of studies eventually yield information for analyses that improve future education. 


\section{Method}

A mixed-method design was conducted with students from six different disciplinary schools: School of Science and Engineering; School of Business; School of Architecture, Art and Design; School of Social Sciences; School of Humanities and Education; and School of Medicine and Health Sciences. For the quantitative analysis, a questionnaire was designed to evaluate students' perspectives about the distance modality implemented due to social distancing contingencies. The five constructs considered in the research instrument were pedagogy, collaboration, learning resources, time management, and functional features. A reliability test was conducted, yielding the estimated Cronbach's Alpha of 0.955. The instrument had 17 items rated on a 1-5 Likert scale.

For the qualitative analysis, two open questions were added at the end of the instrument: Mention positive learning experiences, and in your opinion, what aspects do you consider can be improved? The responses were classified into two categories: Positive Experiences and Aspects to Improve.

All higher education students enrolled in at least one course were invited to answer the survey at Qualtrics. The survey was available from May 18 to 25, 2020. Due to low participation, a second invitation was sent, motivating students to answer. It offered new available dates: June 4-10, 2020. In total, 796 students participated in the sample. Their ages were between 17 and 19 years old. Table 1 displays their composition by School.

Table 1: Sample composition by School

\begin{tabular}{lll}
\hline & Students & Percentage \\
\hline School of Science and Engineering & 349 & $43.85 \%$ \\
\hline School of Business & 219 & $27.51 \%$ \\
\hline School of Architecture, Art and Design & 25 & $3.14 \%$ \\
\hline School of Social Sciences & 54 & $6.78 \%$ \\
\hline School of Humanities and Education & 128 & $16.08 \%$ \\
\hline School of Medicine and Health Sciences & 21 & $2.64 \%$ \\
\hline
\end{tabular}

This study was conducted using the ethics protocol suggested by Dooly et al. (2017): The study does not cause potential harm to anyone involved, provides sufficient information to participants to comprehend the research project's scope fully, ensures the confidentiality of all research subjects, and the data was used for educational purposes. So, learners were free to participate in the study. Those who did were informed that their data would be safeguarded and anonymized for finding results. They were also informed that their participation would improve the university's quick response to ensure high-quality education.

\section{Results}

The quantitative and qualitative results of the samples studied are presented in this section. The quantitative research instrument is presented as part of the findings. 


\section{Quantitative findings}

As Olivares et al. (2021) state, academic content is a priority of online courses; when easy-to-use technology is also part of the solution, the students' experiences are expected to be positive. This was the hypothesis of the university's design of the digital educational modality implemented in April 2020; its more than 30 years of experience in offering distance education was a key advantage when migrating all the undergraduate programs to the digital modality.

Table 2 shows the 17 items considered in the designed instrument each item classified into a quality dimension.

Table 2: Quality dimensions when assessing students' perceptions of the digital educational modality

\begin{tabular}{ll}
\hline Quality dimension & Item \\
\hline Pedagogical & $\begin{array}{l}\text { The scheduled activities and the teachers' assistance helped me } \\
\text { to achieve the learning goals, despite the distance. }\end{array}$ \\
\hline $\begin{array}{l}\text { The feedback I receive under the digital modality helped me } \\
\text { improve my performance. }\end{array}$ \\
\hline $\begin{array}{l}\text { Participation in all class sessions through Zoom / Microsoft } \\
\text { Teams added value to my learning. }\end{array}$ \\
\hline Collaboration \\
\hline $\begin{array}{l}\text { The digital modality allowed me to be active in my classes, } \\
\text { providing comments, asking questions, and collaborating with } \\
\text { my classmates. }\end{array}$ \\
$\begin{array}{l}\text { The different interaction options established through the } \\
\text { digital modality facilitated the teaching-learning process. }\end{array}$ \\
\hline $\begin{array}{l}\text { Classes under the digital modality developed naturally, like a } \\
\text { face-to-face class, in terms of schedules and interaction. }\end{array}$ \\
\hline Learning Resources & $\begin{array}{l}\text { The use of different technological applications during my } \\
\text { classes helped me to understand the contents better. }\end{array}$ \\
\hline $\begin{array}{l}\text { The contents provided by teachers during the sessions under } \\
\text { the digital modality facilitated my learning. }\end{array}$ \\
\hline $\begin{array}{l}\text { The digital modality has made it possible to expand how I am } \\
\text { evaluated and the diversity of learning evidence. }\end{array}$ \\
$\begin{array}{l}\text { Class activities were dynamic because they included } \\
\text { innovative elements that captured my interest and motivated } \\
\text { me. }\end{array}$ \\
\hline $\begin{array}{l}\text { The digital modality allowed me to do my learning activities } \\
\text { in different places and times. }\end{array}$ \\
$\begin{array}{l}\text { With the digital modality implementation, I produced the } \\
\text { and self-managed way. }\end{array}$ \\
\hline
\end{tabular}




\begin{tabular}{ll}
\hline & $\begin{array}{l}\text { I have noticed that the digital modality allowed flexible } \\
\text { activities to be included in my classes. }\end{array}$ \\
\hline Functional Features & $\begin{array}{l}\text { The Zoom tool's interface was user-friendly, allowing me to } \\
\text { participate without a problem during my sessions. }\end{array}$ \\
\hline $\begin{array}{l}\text { I believe that the Canvas platform facilitated the teaching and } \\
\text { learning process. }\end{array}$ \\
\hline $\begin{array}{l}\text { The technological tools used in the digital modality facilitated } \\
\text { my communication with classmates. }\end{array}$ \\
\hline
\end{tabular}

The Likert scale ranged from 1 to 5 , where 5 was the maximum rating for students' perception. The estimated mean for each item was below 4 . The item with the highest mean was, The Zoom tool's interface was user-friendly, allowing me to participate without a problem during my sessions (3.94). The lowest one was, Class activities were dynamic because they included innovative elements that captured my interest and motivated me (2.52).

The results for the Quality dimensions means, estimated for each category and organized in ascending order, were: Collaboration 2.77, Learning Resources 2.96, Pedagogical 3.09, Time Management 3.14 and Functional Features 3.60 (see Figure 2). These findings reveal that students' perception of collaboration during the pandemic is an improvement opportunity for the institution.

The results also highlight that the experienced digital education team selected two robust educational platforms for the digital modality: Canvas and Zoom, both evaluated positively in the Functional Features category.

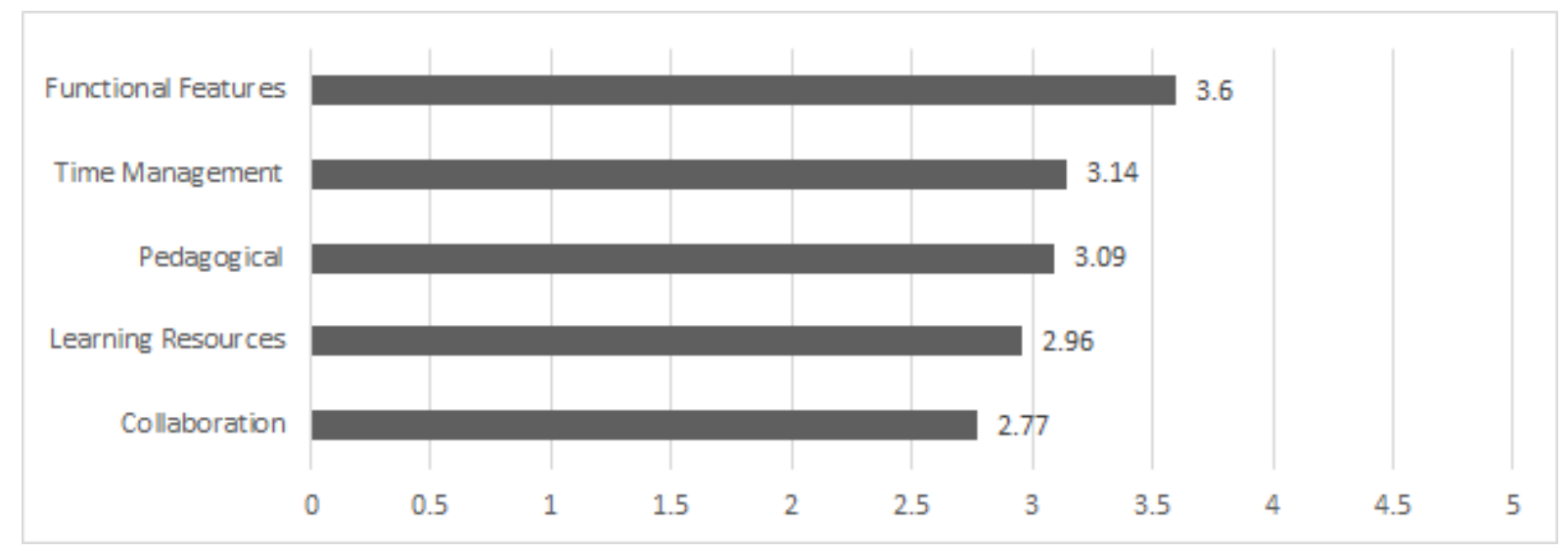

Figure 2: The quality dimensions' means for the digital educational modality.

\section{Qualitative findings}

The qualitative analysis complemented the numeric results of the quantitative perspective. As mentioned before, two open questions were included at the end of the instrument. The first one asked about positive aspects of the learning experience and the second one for improving. The five- 
dimensions model also guided the categorization of both open questions. Table 3 summarizes the most common mentions.

Table 3: The most mentioned Positive Experiences and Aspects to Improve

\begin{tabular}{|c|c|}
\hline \multicolumn{2}{|l|}{ Positive Experiences } \\
\hline Pedagogical & $\begin{array}{l}\text { The effort to continue teaching. } \\
\text { Class adaptation to an attractive digital modality. } \\
\text { Teacher dedication, patience, disposition, and motivation of the } \\
\text { students. }\end{array}$ \\
\hline Collaboration & $\begin{array}{l}\text { Communication with professors and colleagues. } \\
\text { Speed in resolving questions. }\end{array}$ \\
\hline Learning Resources & $\begin{array}{l}\text { The recording of the sessions allowed students to review the } \\
\text { contents several times. }\end{array}$ \\
\hline Functional Features & The Zoom tool made the learning process easier. \\
\hline Time Management & $\begin{array}{l}\text { Flexible class schedule. } \\
\text { View class from anywhere. } \\
\text { Ease of movement. } \\
\text { The flexibility of consults with teachers. }\end{array}$ \\
\hline \multicolumn{2}{|l|}{ Aspects to Improve } \\
\hline Pedagogical & $\begin{array}{l}\text { Design of interactive, simple, innovative, practical, dynamic, } \\
\text { participatory, and flexible activities adapted to a digital modality } \\
\text { and updated in Canvas. } \\
\text { Less extensive content adapted to the model, more depth in the } \\
\text { topics, and a reduced agenda. }\end{array}$ \\
\hline Collaboration & Prompt and personalized feedback. \\
\hline Learning Resources & Laboratories activities in a face-to-face format. \\
\hline Functional Features & $\begin{array}{l}\text { Teacher training in technology (Canvas and Zoom), pedagogy } \\
\text { (didactics), and adapting classes to the model. }\end{array}$ \\
\hline Time Management & $\begin{array}{l}\text { Reduce the duration of classes. } \\
\text { Avoid spending too much time in front of the computer. } \\
\text { Include breaks during and between classes. }\end{array}$ \\
\hline
\end{tabular}

The qualitative results reinforced what the quantitative analysis revealed. Students recognized the effort made by the University and its professors to ensure the continuity of teaching during the social distancing regulations caused by the pandemic. They also identified that the Zoom platform made learning easier; they benefitted from access to the recorded classes, which helped them review what had been studied in the synchronous sessions.

The responses to the open question, in your opinion, what aspects do you consider can be improved? were of great relevance to the institution. These comments from the first quick digital solution implemented are input to construct a more robust solution for the more than fifty thousand undergraduate students nationwide on the University's campuses. During summer 2020, the six national Schools mentioned previously improved the online modality adaption, developing more attractive and innovative learning resources. A significant effort was made to train teachers; a set of courses was declared as basic training for them, and only those who received the training were programmed for the August-December 2020 semester. Last but not least, time management was 
crucial during the pandemic. Professors were invited to use time efficiently in the Zoom sessions, remembering that assigning homework means students spend additional time in front of their monitors. They were advised to include a short break during their sessions.

\section{Discussion and Conclusions}

The instrument's design made it possible to collect pertinent information related to the five dimensions previously mentioned in the context of the digital educational modality used in a pandemic. The instrument's data contributed to broadening the vision of the experience that students had under this modality and understanding what they valued most about it.

Research results indicated that students had a favorable perception of the digital modality and the institution's response capacity in the face of the SARS-CoV-2 contingency. The Business School students declared the most favorable perception of the digital modality.

In general, students appreciated Zoom's friendly interface, the Canvas platform's ease of use, and the digital modality's flexibility to study from anywhere and anytime.

The students felt that the digital modality needed to improve the Zoom sessions' duration, the interactions with peers and the teacher, and offer more interactive, dynamic and innovative learning activities.

Although the University had just one week to prepare for the change from a face-to-face educational modality to remote distance learning due to the SARS-CoV-2 lockdown, it succeeded. The students continued their education. From this study's results, it was possible to update and improve a digital education modality beginning in August 2020 to the present for more than fifty thousand higher education students.

The results from this study provided helpful information about the students' learning process and their educational expectations during the pandemic. Some of the recommendations for the five quality dimensions follow.

\section{Pedagogical dimension}

According to the results shown in Table 2, it might be useful to consider the Elzainy et al. (2020) recommendations regarding the e-learning experience during the SARS-CoV-2 pandemic. These include offering sustained monitoring, technical personnel to support faculty and students, updating the e-learning resources, having training programs for improving faculty development, and motivating the students to take on self-directed learning. It is also recommended to use assessment methods so that students can complete the test in a flexible time frame (Özer \& Suna, 2020)

\section{Collaboration dimension}

This study's findings are similar to Rannastu-Avalos and Siiman (2020), noting that it is a challenge for distance learning to facilitate collaborative learning. To elevate collaboration and teamwork in a digital educational modality, educators must design it to be a secure online learning environment that fosters a sense of community among the learners, as Karalis and Raikou (2020) mentioned. 


\section{Learning Resources dimension}

This study's findings make evident how crucial the learning resources are for ensuring a good learning experience. Rephrasing the suggestion of Almaiah et al. (2020) previously, universities must focus on instilling the culture of e-learning systems among students by training them to use educational platforms and digital resources effectively because it leads to the successful adoption of e-learning systems.

\section{Time Management dimension}

To improve time management, one must consider previous authors' suggestion (Almaiah et al., 2020; Rhada et al., 2020) that universities need to ensure that all students and instructors are fully selfefficacious and have the skills to use the system and time wisely.

\section{Functional features dimension}

To build on the results shown in Table 2, educators should consider some suggestions related to functional features from previous authors such as (Aboagye, et al., 2020). These relate to accessibility, the usability of the e-learning system, the expansion of technical support, and verification that the system supports devices or equipment used by students and teachers.

\section{References}

Aboagye, E., Yawson, J. A., \& Appiah, K. N. (2020). COVID-19 and E-Learning: The Challenges of Students in Tertiary Institutions. Social Education Research, 2(1), 1-8. https://doi.org/10.37256/ser.212021422

Aini, Q., Budiarto, M., Putra, P. O. H., \& Rahardja, U. (2020). Exploring E-learning Challenges During the Global COVID-19 Pandemic: A Review. Jurnal Sistem Informasi, 16(2), 57-65.

Almaiah, M.A., Al-Khasawneh, A. \& Althunibat, A. (2020). Exploring the critical challenges and factors influencing the E-learning system usage during the COVID-19 pandemic. Education and Information Technologies, 25, 5261-5280. https://doi.org/10.1007/s10639-020-10219-y

Bandaranaike, S. U. N. I. T. I., Orozco Quijano, E. P., \& Navarrete-Baez, F. E. (2020). A COVID-19 work-integrated learning strategy for entrepreneurial mindset reflections: Case study in Mexico. International Journal of Work-Integrated Learning, 21(4), 467-489.

Bergdahl, \& Nouri, J. (2020). Covid-19 and crisis-prompted distance education in Sweden. Technology, Knowledge and Learning, 1-17. https://doi.org/10.1007/s10758-020-09470-6

Buzgan, T. \& Güner, O. (2020). The Effectiveness of the World Health Organization in Pandemics and the Future of the Post-Pandemic Era. In M. Şeker, A. Özer and C. Korkut (Ed.), Reflections on the pandemic in the Future of the World (pp. 95-114). TÜBA

Dooly, M., Moore, E., \& Vallejo, C. (2017). Research ethics. In E. Moore \& M. Dooly (Eds.), Qualitative approaches to research on plurilingual education (pp. 351-362). Researchpublishing.net. https://doi. org/10.14705/rpnet.2017.emmd2016.634

Elzainy, A., El Sadik, A., \& Al Abdulmonem, W. (2020). Experience of e-learning and online assessment during the COVID-19 pandemic at the College of Medicine, Qassim University. Journal of Taibah University Medical Sciences, 15(6), 456-462.

Kamal, A. A., Shaipullah, N. M., Truna, L., Sabri, M., \& Junaini, S. N. (2020). Transitioning to Online Learning during COVID-19 Pandemic: Case Study of a Pre-University Centre in Malaysia. International Journal of Advanced Computer Science and Applications, 217-223. 
Karalis, T., \& Raikou, N. (2020). Teaching at the times of COVID-19: Inferences and Implications for Higher Education Pedagogy. International Journal of Academic Research in Business and Social Sciences, 10(5), 479-493.

Minghat, A. D., Ana, A., Purnawarman, P., Saripudin, S., Muktiarni, M., Dwiyanti, V., \& Mustakim, S. S. (2020). Students' Perceptions of the Twists and Turns of E-learning in the Midst of the Covid 19 Outbreak. Revista Romaneasca pentru Educatie Multidimensionala, 12(2), 15-26.

Olivares, S.L., Hernández, R.I.E., Corolla, M.L.T. et al.(2021). MOOC Learning Assessment in Clinical Settings: Analysis from Quality Dimensions. Medical Science Educator, 31(2), 557455. https://doi.org/10.1007/s40670-020-01178-7

Özer, M., \& Suna, E. (2020). COVID-19 Pandemic and Education. In M. Şeker, A. Özer and C. Korkut (Ed.), Reflections on the pandemic in the Future of the World (pp. 157-178). TÜBA

Radha, R., Mahalakshmi, K., Kumar, V. S., \& Saravanakumar, A. R. (2020). E-Learning during the lockdown of the Covid-19 pandemic: A global perspective. International journal of control and automation, 13(4), 1088-1099.

Rannastu-Avalos, M., \& Siiman, L. A. (2020, September). Challenges for Distance Learning and Online Collaboration in the Time of COVID-19: Interviews with Science Teachers [Paper presentation]. 26th International Conference on Collaboration Technologies and Social Computing (pp. 128-142). Springer, Cham.

Reimers, F. M., \& Schleicher, A. (2020). A framework to guide an education response to the COVID19 Pandemic of 2020. OECD. https://www.oitcinterfor.org/node/7803

Şeker, M. (2020). Primum non nocere! In M. Şeker, A. Özer and C. Korkut (Ed.), Reflections on the pandemic in the Future of the World (pp. 9-12). TÜBA

Tecnologico de Monterrey (2020, June 6). Tec de Monterrey Launches a Flexible and Digital Model for More Than 90 Thousand Students. Observatory of Educational Innovation. https://observatory.tec.mx/edu-news/tec-de-monterrey-launches-flexible-and-digitalmodel?rq=flexible

UNESCO (2020). COVID-19 Educational Disruption and Response. https://en.unesco.org/covid19/educationresponse.

Zhu, X., \& Liu, J. (2020). Education in and after Covid-19: Immediate responses and long-term visions. Postdigital Science and Education, 2(3), 695-699. 